\title{
Formation of copper tin sulfide films by pulsed laser deposition at 248 and $355 \mathrm{~nm}$
}

Ettlinger, Rebecca Bolt; Crovetto, Andrea; Canulescu, Stela; Cazzaniga, Andrea Carlo; Ravnkilde, Lasse; Youngman, Tomas Hugh; Hansen, Ole; Pryds, Nini; Schou, Jørgen

Published in:

Applied Physics A: Materials Science \& Processing

Link to article, DOI:

10.1007/s00339-016-9939-4

Publication date:

2016

Document Version

Peer reviewed version

Link back to DTU Orbit

Citation (APA):

Ettlinger, R. B., Crovetto, A., Canulescu, S., Cazzaniga, A. C., Ravnkilde, L., Youngman, T. H., Hansen, O., Pryds, N., \& Schou, J. (2016). Formation of copper tin sulfide films by pulsed laser deposition at 248 and $355 \mathrm{~nm}$. Applied Physics A: Materials Science \& Processing, 122(4), 1-10. https://doi.org/10.1007/s00339-016$9939-4$

\section{General rights}

Copyright and moral rights for the publications made accessible in the public portal are retained by the authors and/or other copyright owners and it is a condition of accessing publications that users recognise and abide by the legal requirements associated with these rights.

- Users may download and print one copy of any publication from the public portal for the purpose of private study or research.

- You may not further distribute the material or use it for any profit-making activity or commercial gain

- You may freely distribute the URL identifying the publication in the public portal 
Applied Physics A - Special issue for the COLA-conference 2015, CAIRNS Australia

\title{
Formation of copper tin sulfide films by pulsed laser deposition at $248 \mathrm{~nm}$ and 355 nm
}

Rebecca Bolt Ettlinger ${ }^{1}$, Andrea Crovetto ${ }^{2}$, Stela Canulescu ${ }^{1}$, Andrea Cazzaniga ${ }^{1}$, Lasse Ravnkilde ${ }^{2}$, Tomas Youngman ${ }^{2}$, Ole Hansen ${ }^{2}$, Nini Pryds ${ }^{3}$, and Jørgen Schou ${ }^{1}$

${ }^{1}$ DTU Fotonik, Technical University of Denmark, DK-4000 Roskilde, Denmark

${ }^{2}$ DTU Nanotech, Technical University of Denmark, DK-2800 Kgs. Lyngby, Denmark

${ }^{3}$ DTU Energy, Technical University of Denmark, DK-4000 Roskilde, Denmark

*reet@fotonik.dtu.dk, +45 4677 4587, DTU Fotonik, Frederiksborgvej 399, DK-4000 Roskilde, Denmark

\begin{abstract}
The influence of the laser wavelength on the deposition of copper tin sulfide (CTS) and SnS-rich CTS with a 248-nm KrF excimer laser (pulse length $\tau=20 \mathrm{~ns}$ ) and a 355-nm frequency-tripled Nd:YAG laser ( $\tau=6 \mathrm{~ns}$ ) was investigated. A comparative study of the two UV wavelengths shows that the film growth rate per pulse of CTS was three to four times lower with the $248 \mathrm{~nm}$ laser than the $355 \mathrm{~nm}$ laser. SnSrich CTS is more efficiently ablated than pure CTS. Films deposited at high fluence have sub-micron and micrometer size droplets, and their size and area density do not vary significantly from 248 to 355 $\mathrm{nm}$ deposition. Irradiation at low fluence resulted in a non-stoichiometric material transfer with significant $\mathrm{Cu}$-deficiency in the as-deposited films. We discuss the transition from a non-stoichiometric material transfer at low fluence to a nearly stoichiometric ablation at high fluence based on a transition from a dominant evaporation regime to an ablation regime.
\end{abstract}

Keywords (max 6): PLD; pulsed laser deposition; droplets; particulates; laser wavelength; copper tin sulfide; $\mathrm{Cu}_{2} \mathrm{SnS}_{3}$ 


\section{Contributing author email addresses:}

Rebecca Bolt Ettlinger, reet@ffotonik.dtu.dk, Andrea Crovetto, ancro@nanotech.dtu.dk; Stela Canulescu, stec@fotonik.dtu.dk; Andrea Cazzaniga, andcan@fotonik.dtu.dk; Lasse Ravnkilde, s122729@student.dtu.dk; Tomas Youngman, s123603@student.dtu.dk; Ole Hansen, ole.hansen@nanotech.dtu.dk; Nini Pryds, nipr@dtu.dk; Jørgen Schou, josc@fotonik.dtu.dk

\section{PACS numbers:}

$81.15 \mathrm{Fg}$

73.50.Pz

88.40.jn 


\section{Introduction}

Research in thin film solar cells based on p-type semiconductors has mainly been focused on $\mathrm{Cu}(\mathrm{In}, \mathrm{Ga})(\mathrm{S}, \mathrm{Se})_{2}(\mathrm{CIGS})$ and $\mathrm{CdTe}$. However, due to the limited availability of elements like In and Te and the toxicity of $\mathrm{Cd}$, alternative absorbers such as $\mathrm{Cu}_{2} \mathrm{ZnSnS}_{4}(\mathrm{CZTS})$ are being investigated [1], and recently a thin film solar cell based on a CZTS absorber layer has reached an efficiency of 8.8\% [2]. Other p-type semiconductors with fewer elements are also available, including members of the ternary $\mathrm{Cu}-\mathrm{Sn}-\mathrm{S}$ system [3]. Among the $\mathrm{Cu}-\mathrm{Sn}-\mathrm{S}$ compounds, $\mathrm{Cu}_{2} \mathrm{SnS}_{3}$ (CTS) has been suggested as potential solar cell absorber because it has an absorption coefficient comparable to CZTS and a band gap of 0.9$1.35 \mathrm{eV}$ depending on the crystal structure [4-6]. The highest efficiency of CTS solar cells of $4.65 \%$ was achieved by thermal evaporation [7]. CTS thin films have also, more recently, been fabricated by pulsed laser deposition (PLD) [8]. Vanalakar et al. [9] have reported on the first CTS solar cell prepared by pulsed laser deposition with an efficiency of $0.82 \%$.

PLD is a suitable technique for deposition of films with complex structures [10]. The presence of droplets (in some papers called particulates) in the growing films is a well-known problem, which can be addressed in a number of ways [11]. Particularly, droplets up to 1 micron in diameter or larger were observed in the films of CTS deposited by PLD [8,9]. The influence of droplets on the overall efficiency of the solar cell is not well understood, but it is clear that it can be detrimental for the cell performance for the following reasons: i) the droplet size can be larger than the overall thickness of the absorber layer, resulting in a rough interface and possible shunt paths between the CTS film and subsequent solar cell layers [12]; and ii) the droplets can have a different composition than the matrix of the CTS film $[13,14]$, resulting in non-homogeneity in composition and therefore different charge carrier transport properties.

Round droplets of micrometer or sub-micrometer size result from solidification of molten droplets ejected from the target by laser-induced recoil pressure or sub-surface boiling [11]. A common approach to minimize droplets is to reduce the irradiation wavelength, as previously reported for $\mathrm{Si}$ [15], $\mathrm{ZnO}$ [16] and $\mathrm{YBa}_{2} \mathrm{Cu}_{3} \mathrm{O}_{7-\mathrm{x}}$ (YBCO) [17,18] with comparisons of PLD using IR, visible and UV laser wavelengths. Several mechanisms have been proposed to explain the better morphology of films deposited at UV wavelengths. First, the absorption depth $\left(\alpha^{-1}\right)$ in the material is usually short at UV wavelengths resulting in a thin layer being ablated and thus formation of a hot plasma plume [17]. 
Second, if the absorption does not vary significantly with irradiation wavelength, droplet minimization may result from absorption of UV light by the droplets in the near-surface region, resulting in fragmentation down to a very small size. The second mechanism may be more dominant when comparing the morphology of films deposited at different UV wavelengths [17].

Apart from changing the laser wavelength, it is also known that a reduction in fluence can lead to a reduction in droplet area density and size [19]. A reduction in droplet density and size with a reduction of the fluence from $1.5 \mathrm{~J} / \mathrm{cm}^{2}$ to $0.7 \mathrm{~J} / \mathrm{cm}^{2}$ has been seen in PLD of CZTS with a $248 \mathrm{~nm}$ laser by Moriya et al. [20] and with a reduction in fluence from 4 to $0.5 \mathrm{~J} / \mathrm{cm}^{2}$ on CZTS using a $355 \mathrm{~nm}$ laser by Sulaiman et al. [13]. Pawar et al. also observed smaller and fewer droplets at $1 \mathrm{~J} / \mathrm{cm}^{2}$ than at 1.5 and 2 $\mathrm{J} / \mathrm{cm}^{2}$ using a $248 \mathrm{~nm}$ laser with CZTS [21]. Similarly, Ujimoto et al. observed a reduction in droplet density from 1.5 to $0.5 \mathrm{~J} / \mathrm{cm}^{2}$ using a $193 \mathrm{~nm}$ excimer laser to deposit $\mathrm{BiFeO}_{3}$, while noting that in their case droplets could not be completely avoided simply by decreasing laser fluence [22].

The aim of this paper is to examine the influence of two different UV laser wavelengths on the deposition rate and the size, density and composition of the droplets in films deposited by PLD from targets of CTS and SnS-enriched CTS. The SnS-rich composition was chosen for comparison because deficiency of Sn and S had previously been observed in CTS films deposited with $355 \mathrm{~nm}$ laser irradiation [8].

\section{Materials and methods}

\subsection{Pulsed laser deposition}

Pulsed laser deposition was carried out using a Nd:YAG laser operating at $355 \mathrm{~nm}$ (third harmonic) with a pulse duration of 5-7 ns and a $\mathrm{KrF}$ excimer laser operating at $248 \mathrm{~nm}$ with a pulse duration of 20 ns (see Figure 1 and Table 1). The depositions were made in vacuum at a pressure of $1-5 \times 10^{-6}$ mbar. The target was placed at an angle of $45^{\circ}$ with respect to the incoming laser beam and the beam was rastered across the target. The substrate material was Mo-coated soda lime glass, which is typically

used for CTS solar cell preparation. The fluence was varied from 0.2 to $2.3 \mathrm{~J} / \mathrm{cm}^{2}$ and was calculated based on a measurement of the spot size on a $\mathrm{Cu}$ foil. The substrate-target distance was $4-4.5 \mathrm{~cm}$ due to constraints in the setups for ensuring similar deposition conditions. Films made with a target-substrate distance of $4 \mathrm{~cm}$ up to $7.5 \mathrm{~cm}$ using the $355 \mathrm{~nm}$ laser were similar in composition and droplet density (not shown), as expected for depositions made in vacuum [19]. 
Single samples were made at different fluence values and spot sizes. The representativeness of the single samples was verified by repeated depositions of some of the films under identical circumstances. With the $355 \mathrm{~nm}$ laser and the SnS-rich CTS target, nine films were made under exactly the same circumstances, confirming that the deposition rate, droplet density (appearance in SEM) and composition were reproducible. With the non-SnS-enriched CTS target, films made at $1.6 \mathrm{~J} / \mathrm{cm}^{2}$ were reproduced with both lasers and it was confirmed that samples produced under the same circumstances were similar regarding thickness, droplet density and composition.

The number of pulses at the two different wavelengths was adjusted to deposit films sufficiently thick for reliable energy dispersive X-ray spectroscopy (EDX) at most fluences. According to the model CASINO [23], $99 \%$ of the EDX signal for CTS derives from below $900 \mathrm{~nm}$ thickness and $90 \%$ from below $750 \mathrm{~nm}$ assuming a smooth surface and a bulk density of $5.02 \mathrm{~g} / \mathrm{cm}^{3}$ for $\mathrm{Cu}_{2} \mathrm{SnS}_{3}$ [24].

Multicomponent targets of CTS and SnS-rich CTS were purchased from PVD products. The targets named "CTS" in the present work had a Cu:Sn:S ratio of about 2:1:2.5 (measured by EDX; see Table 2) while the one called "SnS-rich CTS" had a Cu:Sn:S ratio of about 1:2:3. The targets consist of multiple crystalline phases identified by XRD including $\mathrm{Cu}_{2} \mathrm{SnS}_{3}$ (tetragonal, JCPDS 89-4714), $\mathrm{SnS}$ (cubic, JCPDS 89-2755, and orthorhombic, JCPDS 75-1803), CuS (cubic, JCPDS 78-877) and $\mathrm{Cu}_{2} \mathrm{~S}$ (cubic, JCPDS 53-522). EDX mapping of the targets showed regions of hundreds of micrometers in diameter with either $\mathrm{Cu}$ rich composition, $\mathrm{Sn}$ rich composition, or a mixture of different phases.

\subsection{Characterization}

The deposition rates were measured with quartz crystal microbalances (QCM, Colnatec, Inc) and converted to film thickness assuming a bulk density of $5.02 \mathrm{~g} / \mathrm{cm}^{3}$ for both $\mathrm{Cu}_{2} \mathrm{SnS}_{3}$ and SnS-rich CTS. ( the bulk density of $\mathrm{SnS}$ of $5.08 \mathrm{~g} / \mathrm{cm}^{3}$ is similar to that of CTS) [24,25]. The targets were pre-ablated by 15.000-18.000 pulses before measurement of the deposition rate in order to ensure a stable deposition. As shown in Table 1, the ablation parameters were similar for the comparison of the deposition rate between the different wavelengths. The deposition rates measured by QCM were systematically larger (by about 20-30\%) than the deposition rates determined from thickness measurements of films made at different fluence values (data not shown). This was most likely due to the measurement method: in SEM the measurement excluded droplets sticking up above the film 
surface while Dektak measurements are not highly accurate for surfaces with a high density of micrometer-scale droplets.

X-ray diffraction measurements (XRD) were carried out with a Bruker D8 diffractometer in BraggBrentano configuration using $\mathrm{Cu} \mathrm{K}_{\alpha}$ and $\mathrm{Cu} \mathrm{K} \mathrm{K}_{\beta}$ radiation. The diffraction pattern of the as-deposited films was measured using a step size of $0.03^{\circ}$ and a rate of $0.33 \mathrm{step} / \mathrm{s}$.

Scanning electron microscopy was performed at 5-15 kV using the in-lens and secondary electron detectors of two SEMs equipped with field emission guns (FE-SEM, Supra 60VP and Supra 35, Zeiss). The droplet size distributions were determined by processing SEM images of 20 x $30 \mu \mathrm{m}$ size with image analysis software (ImageJ). The droplets were discriminated from the homogeneous film using a semi-automatic procedure with the signal intensity contrast as selection criterion, and the area of each droplet was calculated automatically. Energy dispersive X-ray spectroscopy (EDX) was performed at $15 \mathrm{kV}$ in a Hitachi TM3000 table top SEM using a built-in Bruker detector with Quantax 70 software that performed mapping and quantification of the element ratios with $\mathrm{Cu} \mathrm{K}$-lines. Additional EDX measurements were performed in the Supra 60VP SEM with a silicon drift detector $\left(X-M^{N}{ }^{\mathrm{N}} 50\right.$, Oxford Instruments), which allowed measurement on specific areas identified in SEM images of the films including individual droplets. From the Supra/ X-Man ${ }^{\mathrm{N}} 50$ data, element ratios were calculated by Oxford Instrument's Aztec software using the $\mathrm{Cu}$ K-lines, and deconvoluting any Mo contribution to the $\mathrm{S}$ peak.

\section{Results}

\subsection{Deposition rates}

The deposition rate of CTS and SnS-rich CTS as a function of laser fluence is shown in Fig. 2. At any given fluence, the deposition rate of CTS and SnS-rich CTS at $355 \mathrm{~nm}$ is three to four times higher than at $248 \mathrm{~nm}$.

Two main factors may explain the difference in deposition rate between the two lasers. Firstly, the effective intensity at $248 \mathrm{~nm}\left(1.2 \times 10^{8} \mathrm{~W} / \mathrm{cm}^{2}\right)$ was about three times lower than at $355 \mathrm{~nm}\left(3.8 \times 10^{8}\right.$ $\mathrm{W} / \mathrm{cm}^{2}$ ) due to the longer pulse duration at $248 \mathrm{~nm}$. Secondly, the photon energy of $5 \mathrm{eV}$ (corresponding to $248 \mathrm{~nm}$ ) and $3.5 \mathrm{eV}$ (corresponding to $355 \mathrm{~nm}$ ) is much larger that the band gap energy of the constituent phases of the target, which was mainly composed of $\mathrm{SnS}, \mathrm{CuS} \mathrm{Cu}_{2} \mathrm{~S}$ and 
tetragonal-phase $\mathrm{Cu}_{2} \mathrm{SnS}_{3}$ (see Section 2.1) [4,26,27]. However, it is possible that the absorption coefficient of the individual phases varies from $248 \mathrm{~nm}$ to $355 \mathrm{~nm}$ even though the photon energies are greater than the band gap energy. For example, for a mixture of the two related phases, cubic-phase and monoclinic-phase $\mathrm{Cu}_{2} \mathrm{SnS}_{3}$, the absorption coefficient was found to vary by a factor 3 from $1.6 \times 10^{5} \mathrm{~cm}^{-}$ ${ }^{1}$ at $3.5 \mathrm{eV}$ to $4.3 \times 10^{5} \mathrm{~cm}^{-1}$ at $5 \mathrm{eV}$ [28]. For SnS, the absorption coefficient varies less between the two wavelengths (both approx. $1 \times 10^{6} \mathrm{~cm}^{-1}$ as estimated from plots of the dielectric functions) [29]. The variation in the absorption coefficient means that the light penetration depth may vary from phase to phase in the target. Overall, the lower deposition yield at $248 \mathrm{~nm}$ compared to $355 \mathrm{~nm}$ probably may be attributed to the lower laser intensity, possibly in combination with a smaller light penetration depth in some of the phases in the target.

Figure 2 furthermore shows that the deposition of SnS-rich CTS (Cu:Sn:S 1:2:3) was faster than the deposition of CTS (Cu:Sn:S 2:1:2.5), independent of the irradiation wavelength. This is expected since both $\mathrm{S}$ and $\mathrm{SnS}$ have a higher vapor pressure than the copper-containing phases in the target [30,31]. An increase in the concentration of high vapor pressure components in the target results in a higher ablation yield $[10,11]$.

\subsection{Droplets}

SEM images of several CTS and SnS-rich CTS films deposited at a laser fluence of 0.2-1.8 J/cm 2 are shown in Fig. 3 a-f. The surface of the films is covered with large circular droplets ranging from tens of nanometers to several microns in diameter. Our findings indicate that at a given fluence, the surface morphology of the as-deposited CTS films does not vary significantly from $355 \mathrm{~nm}$ to $248 \mathrm{~nm}$. On the other hand, a decrease in the laser fluence to $0.2 \mathrm{~J} / \mathrm{cm}^{2}$ results in a decrease in the size and density of the droplets at both wavelengths (Fig. 3 e-f).

The size distribution of the droplets extracted from SEM images in Fig. $3 \mathrm{c}, \mathrm{d}$, e and $\mathrm{f}$ is shown in Fig. 4. Note that we could not accurately identify small $(<200 \mathrm{~nm})$ particulates nor overlapping droplets by this method. The incidence of large droplets is also determined with a considerable uncertainty in the histograms as they were relatively rare. Nonetheless, Fig. 4 indicates that there is no reduction in droplet area density for the $248 \mathrm{~nm}$ laser compared to the $355 \mathrm{~nm}$ laser. At high laser fluence, the distribution profile is broad while at low fluence, the average size of the droplets decreases. The data 
suggest that the size and density of the droplets are strongly dependent on the laser energy and for a given fluence, less dependent on the UV irradiation wavelength. This will be discussed in Section 4.

No diffraction peaks were observed beside $\mathrm{Mo}$ and $\mathrm{MoO}_{\mathrm{x}}$ in X-ray diffractograms of the asdeposited films, indicating that the films were mostly amorphous (X-ray data not shown).

\subsection{Composition}

Sulfur content: The CTS films deposited at high fluence $\left(1.5-1.6 \mathrm{~J} / \mathrm{cm}^{2}\right)$ show S-deficiency and the deficiency appears to be larger at $355 \mathrm{~nm}$ than at $248 \mathrm{~nm}$ (Table 2). In contrast, the S content increased markedly in the films made at low fluence $\left(0.5 \mathrm{~J} / \mathrm{cm}^{2}\right.$ with the $355 \mathrm{~nm}$ and $0.2 \mathrm{~J} / \mathrm{cm}^{2}$ with the $248 \mathrm{~nm}$ laser). Thus the $\mathrm{S}$-content increased from $\mathrm{S} /(\mathrm{Cu}+\mathrm{Sn})=0.8 \pm 0.2$ in the target to $\mathrm{S} /(\mathrm{Cu}+\mathrm{Sn})=1.5 \pm 0.6$ in the film made at $0.5 \mathrm{~J} / \mathrm{cm}^{2}$ by the $248 \mathrm{~nm}$ laser.

Metal content: The $\mathrm{Cu} / \mathrm{Sn}$ ratio of the target is maintained within the error bar in the CTS films made at $1.6 \mathrm{~J} / \mathrm{cm}^{2}$ by the $355 \mathrm{~nm}$ laser (Table 2). In comparison, the CTS film deposited at $248 \mathrm{~nm}$ at a similar fluence has a somewhat lower $\mathrm{Cu}$-concentration, though still within the error bar. The low fluence depositions resulted in CTS films with a significant $\mathrm{Cu}$ deficiency at both wavelengths. The $\mathrm{Cu} / \mathrm{Sn}$ ratio varies from $1.1 \pm 0.1$ for films made at $0.2-0.5 \mathrm{~J} / \mathrm{cm}^{2}$ at $355 \mathrm{~nm}$ to only $0.4 \pm 0.1$ for a film made at $0.5 \mathrm{~J} / \mathrm{cm}^{2}$ at $248 \mathrm{~nm}$. These values should be compared with the $\mathrm{Cu} / \mathrm{Sn}$ ratio in the target of 2.3 \pm 0.5 . As a general trend, we observe that as the incident laser energy is reduced, incongruent evaporation becomes dominant, and the $\mathrm{Cu}$ content in the as-deposited films decreases progressively (see Section 4). We have previously reported a similar but less dramatic increase in the S- and Sncontent of films made at low fluence with the $355 \mathrm{~nm}$ laser [8].

Composition of SnS-rich films: The composition of the SnS-rich films does not vary much for films made at fluences between 0.7 and $2.3 \mathrm{~J} / \mathrm{cm}^{2}$ with the $355 \mathrm{~nm}$ laser or for films made at $1-1.8 \mathrm{~J} / \mathrm{cm}^{2}$ for the $248 \mathrm{~nm}$ laser. In general, the films appear S- and Sn-poor compared to the target, but highly Sn-rich $(\mathrm{Cu} / \mathrm{Sn} \sim 0.6)$ as well as somewhat S-poor compared to the desired stoichiometry of $\mathrm{Cu}_{2} \mathrm{SnS}_{3}$.

Composition of droplets: The chemical composition versus the diameter of the droplets of the CTS films deposited at $1.6 \mathrm{~J} / \mathrm{cm}^{2}$ at $248 \mathrm{~nm}$ is shown in Fig. 5. EDX measurements were carried out on a random selection of individual droplets with an average diameter larger than $1 \mu \mathrm{m}$. Fig. 5 indicates a significant deficiency of $\mathrm{S}$ and $\mathrm{Sn}$, and consequently enrichment of $\mathrm{Cu}$ in the $\mathrm{Cu}-\mathrm{Sn}$-S droplets. Despite the scattering of the data due to the relatively high uncertainty of the EDX analysis, we note that the 
deficiency of $\mathrm{S}$ and $\mathrm{Sn}$ increases as the droplet size decreases. The underlying film denoted by the "matrix" in Fig. 5 shows enrichment in the Sn content relative to the average target composition, which may derive from Sn loss from the droplets or from more efficient ablation of the Sn-rich phases in the target compared to the $\mathrm{Cu}$-rich phases. The underlying film matrix is still slightly $\mathrm{S}$ deficient relative to the target, suggesting that sulfur losses occur both by evaporation from the film and by sulfur-deficient droplet solidification into the film.

It should be noted that the spot size was increased from $2.2 \mathrm{~mm}^{2}$ to $5 \mathrm{~mm}^{2}$ in order to deposit films at low fluence due to the low deposition rate. The change in spot size may have had some influence on the off-axis composition, as the ablation plume becomes more forward-directed when the spot size is increased. However, we have in the present work is considered the on-axis composition.

\section{Discussion}

Our ablation studies of CTS and SnS-rich CTS films indicate that the number of droplets is significantly reduced at lower laser fluence, while the irradiation wavelength does not significantly influence the surface morphology of the as-deposited CTS films. We observe a reduction in the average size of the droplets at low laser fluence accompanied by a change to non-stoichiometric material transfer with an increase in the S- and Sn-content. This trade-off between congruent material transfer and the amount of droplets on the films depending on fluence was previously mentioned in the literature, e.g., by Lowndes [11].

An incongruent transfer at low fluence has been observed for other materials (e.g., SrTiO3 [32,33] and YBCO [34]) and different explanatory models have been offered [11,33,34]. Venkatesan et al. pointed out that the non-stoichiometric transfer of the material in the low fluence regime is correlated with preferential evaporation of the elements with high vapor pressure and low cohesive energy in the multicomponent target [34]. In the case of CTS, Cu has a higher cohesive energy ( $3.5 \mathrm{eV} /$ atom) than $\mathrm{Sn}$ (3.12 eV/atom) (Table 3) [35]. While the cohesive energy of atoms in alloys has only been investigated by a few groups, alloyed atoms nevertheless show a cohesive energy similar to the pure elements [10]. Therefore it may be expected that in the evaporative regime, the CTS films are $\mathrm{Cu}$-deficient, as seen in the low-fluence films, as this is the least volatile element and thus the most difficult one to ablate. 
In the high-fluence regime, ablation results in in a distribution of droplets of the order of micrometer size embedded in the CTS films, independent on the irradiation wavelength. In this regime, the transfer of the ablated material is nearly stoichiometric. The films deposited at $355 \mathrm{~nm}$ are slightly $\mathrm{Cu}-$ and $\mathrm{Sn}-$ rich, while the films deposited at $248 \mathrm{~nm}$ are slightly $\mathrm{Cu}$-poor. The lower $\mathrm{Cu}$-content of the $248 \mathrm{~nm}$ films may be linked to the lower intensity of the $248 \mathrm{~nm}$ laser pulses, since this would lead to a higher evaporative component for a given fluence. Interestingly, Kautek et al. saw a similar trend in YBCO films made at $266 \mathrm{~nm}$ and $355 \mathrm{~nm}$ : the element transfer was incongruent at somewhat higher fluence at $266 \mathrm{~nm}$ than at $355 \mathrm{~nm}$, even though in their experiment, both lasers had the same pulse length [18].

Our observation of a transition from a $\mathrm{Cu}$-poor to a $\mathrm{Cu}$-rich regime with increasing fluence with the $355 \mathrm{~nm}$ laser is similar to the transition from Sr-rich to Ti-rich $\mathrm{SrTiO}_{3}$ seen by Ohnishi et al. with increasing fluence [32]. For the deposition of a bi-metallic material in an oxygen background gas, it was possible for Onishi et al. to identify a fluence that perfectly balanced the Sr:Ti ratio. In contrast, for the tri-component chalcogenic material CTS, it may be that no fluence exists that ensures perfectly stoichiometric transfer. However, we see that it is possible tune the ratio of $\mathrm{Sn}$ to $\mathrm{Cu}$ by fluence adjustment and to compensate for any S-deficiency using a post-deposition sulfurization step, as performed for CZTS films by Moriya et al. [20].

Detailed characterization of the droplets embedded in the CTS film deposited at $1.6 \mathrm{~J} / \mathrm{cm}^{2}$ at $248 \mathrm{~nm}$ reveals a large depletion in $\mathrm{S}$ and $\mathrm{Sn}$ relative to $\mathrm{Cu}$ in the droplets. The degree of depletion increases with decreasing droplet size. Sulaiman et al. [13] have observed that both $\mathrm{Cu}$ - and Sn-rich droplets were transferred onto films of CZTS made by PLD at $355 \mathrm{~nm}$ without a detailed qualitative analysis. Chen and Hall [14] have shown that in binary metallic systems of $\mathrm{Nb}-\mathrm{Al}$ and $\mathrm{Nb}-\mathrm{Cr}$, the droplets are usually deficient in the element with high vapor pressure and the deficiency of the volatile elements increases with decreasing droplet size. In the $\mathrm{Cu}-\mathrm{Sn}-\mathrm{S}$ system, the vapor pressure of $\mathrm{Cu}$ and $\mathrm{Sn}$ is much lower than that of S (see Table 3). As a result, preferential evaporation of S is likely and would result in $\mathrm{Cu}$ and Sn-rich droplets. However, the EDX analysis indicates a deficiency of $\mathrm{Sn}$ in the solidified molten droplets in addition to an S-deficiency. Since $\mathrm{SnS}$ is far more volatile than Sn (Table 3), it is likely that the Sn deficiency is caused by the evaporation of $\mathrm{SnS}$, as proposed by Weber et al. in an investigation of Sn-loss from heated films of CZTS [30]).

We do not see a droplet reduction with a change between the two UV laser wavelengths $355 \mathrm{~nm}$ and $248 \mathrm{~nm}$. As described in the introduction, droplet reduction might have been expected if the target 
absorption of the $248 \mathrm{~nm}$ laser were higher than the $355 \mathrm{~nm}$ laser so that subsurface boiling would be reduced, or if the $248 \mathrm{~nm}$ light were able to more efficiently break up the ejected droplets. As discussed in section 3.1 the absorption of different UV wavelengths in the target is not easily predicted, and the increased photon energy at $248 \mathrm{~nm}$ may be offset by the longer pulse length, leading to a lower pulse power. The combined effect of the differences between the lasers in wavelength and pulse length seems to have little influence on this particular material.

For fabrication of the thin film absorber layers of CTS for thin films solar cells, it is desirable to have $\mathrm{Cu}$-poor films [36] and a uniform composition. Since the composition of the droplets can be different to the underlying film, it is important to minimize their occurrence. We observe that splashing and associated $\mathrm{Cu}$-rich droplets can be minimized by reducing the fluence, although the droplet reduction has to be balanced against the appropriate composition. Additional strategies to reduce droplets are to use off-axis deposition, a mechanical velocity filter or a voltage across the ablation plume $[11,19]$. However, these methods mean that the deposition process becomes far more complex.

\section{Conclusion}

We have reported on the fabrication of copper tin sulfide (CTS) and SnS-rich CTS thin films in vacuum for two UV wavelengths, 355 and $248 \mathrm{~nm}$. The deposition rate was about four times higher at $355 \mathrm{~nm}$ than at $248 \mathrm{~nm}$ for both CTS and SnS-rich CTS. The morphology studies of the as-deposited films showed that the area density of the droplets was not reduced by increasing the photon energy from 355 to $248 \mathrm{~nm}$.

For both lasers, the laser fluence significantly affects the density and average size of the droplets. At high fluence $\left(1.6 \mathrm{~J} / \mathrm{cm}^{2}\right)$, UV irradiation leads to near-congruent transfer of the ablated material. Droplets produced by the $248 \mathrm{~nm} \mathrm{KrF-excimer} \mathrm{laser} \mathrm{ablation} \mathrm{at} \mathrm{high} \mathrm{fluence} \mathrm{were} \mathrm{mainly} \mathrm{S}$ and $\mathrm{Sn}$ poor, and the deficiency seemed more pronounced with decreasing droplet size. A reduction in the laser fluence down to $0.2 \mathrm{~J} / \mathrm{cm}^{2}$ resulted in smaller droplets and lower droplet density for both lasers.

The low fluence regime leads to incongruent evaporation of films with typically large copper deficiency and therefore films that were S- and Sn- rich relative to the target. The Cu-deficiency was most pronounced for the $248 \mathrm{~nm}$ laser, possibly due to the lower intensity of the $248 \mathrm{~nm}$ laser pulses.

Films deposited by either laser from the SnS-rich CTS target were Sn-rich relative to the desired $\mathrm{Cu}$ poor composition for solar cell absorber layers. Films deposited from the CTS target at $1.6 \mathrm{~J} / \mathrm{cm}^{2} \mathrm{by}$ 
either laser were somewhat $\mathrm{Cu}$-rich for solar cells (we found $\mathrm{Cu} / \mathrm{Sn} \sim 2.0$ compared to $\mathrm{Cu} / \mathrm{Sn} \sim 1.7-1.9$ in successful solar cells [36,37]). However, by reducing the fluence somewhat it will be possible to reach the optimal $\mathrm{Cu} / \mathrm{Sn}$ ratio with both the $248 \mathrm{~nm}$ and the $355 \mathrm{~nm}$ laser.

Overall our study illustrates the commonly observed trade-off in PLD between reduction in the droplet density and change in composition with a reduction in the laser fluence.

\section{Acknowledgments}

This work has been supported by a grant from the Danish Council for Strategic Research. 


\section{References}

1. D. B. Mitzi, O. Gunawan, T. K. Todorov, and D. A. R. Barkhouse, Phil. Trans. R. Soc. A 371, 20110432 (2013).

2. S. Tajima, T. Itoh, H. Hazama, K. Ohishi, and R. Asahi, Appl. Phys. Express 8, 082302 (2015).

3. T. A. Kuku and O. A. Fakolujo, Sol. Energy Mater. 16, 199 (1987).

4. P. A. Fernandes, P. M. P. Salomé, and A. F. da Cunha, Phys. Status Solidi 7: 3-4, 901 (2010).

5. P. Zawadzki, L. L. Baranowski, H. Peng, E. S. Toberer, D. S. Ginley, W. Tumas, A. Zakutayev, and S. Lany, Appl. Phys. Lett. 103, 253902 (2013).

6. N. Aihara, H. Araki, A. Takeuchi, K. Jimbo, and H. Katagiri, Phys. Status Solidi 10, 1086 (2013).

7. M. Nakashima, J. Fujimoto, T. Yamaguchi, and M. Izaki, Appl. Phys. Express 8, 042303 (2015).

8. R. B. Ettlinger, A. Cazzaniga, S. Canulescu, N. Pryds, and J. Schou, Appl. Surf. Sci. 336, 385 (2015).

9. S. A. Vanalakar, G. L. Agawane, A. S. Kamble, C. W. Hong, P. S. Patil, and J. H. Kim, Sol. Energy Mater. Sol. Cells 138, 1 (2015).

10. J. Schou, Appl. Surf. Sci. 255, 5191 (2009).

11. D. H. Lowndes, in Laser Ablation Desorption, Exp. Methods Phys. Sci. Vol 30, edited by J. C. Miller and R. F. Haglund (Academic Press, New York, 1998), pp. 475-571.

12. K. Ito, in Copp. Zinc Tin Sulfide-Based Thin-Film Sol. Cells, edited by K. Ito, 1st ed. (John Wiley \& Sons, Ltd, 2015), pp. 34-35.

13. N. S. Che Sulaiman, C. H. Nee, S. L. Yap, Y. S. Lee, T. Y. Tou, and S. S. Yap, Appl. Surf. Sci. 354, 42 (2015).

14. L.-C. Chen and E. L. Hall, Mat. Res. Soc. Symp. Proc. 285, 519 (1993).

15. W. O. Siew, S. S. Yap, C. Ladam, Ø. Dahl, T. W. Reenaas, and T. Y. Tou, Appl. Phys. A 104, 877 (2011). 
16. N. J. Ianno, L. McConville, N. Shaikh, S. Pittal, and P. G. Snyder, Thin Solid Films 220, 92 (1992).

17. G. Koren, a. Gupta, R. J. Baseman, M. I. Lutwyche, and R. B. Laibowitz, Appl. Phys. Lett. 55, 2450 (1989).

18. W. Kautek, B. Roas, and L. Schultz, Thin Solid Films 191, 317 (1990).

19. L.-C. Chen, in Pulsed Laser Depos. Thin Film., edited by D. B. Crisey and G. K. Hubler, 1 st ed. (Wiley, 1994), pp. 167-198.

20. K. Moriya, K. Tanaka, and H. Uchiki, Jpn. J. Appl. Phys. 47, 602 (2008).

21. S. M. Pawar, A. V. Moholkar, I. K. Kim, S. W. Shin, J. H. Moon, J. I. Rhee, and J. H. Kim, Curr. Appl. Phys. 10, 565 (2010).

22. K. Ujimoto, T. Yoshimura, A. Ashida, and N. Fujimura, Jpn. J. Appl. Phys. 52, 045803 (2013).

23. D. Drouin, A. R. Couture, D. Joly, X. Tastet, V. Aimez, and R. Gauvin, Scanning 29, 92 (2007).

24. L. I. Berger, in CRC Handb. Chem. Phys., edited by W. M. Haynes, T. J. Bruno, and D. R. Lide, 96th ed. (CRC Press, Taylor and Francis Group, LLT, Boca Raton, FL, 2015), pp. 12-80 - 12-93.

25. W. M. Haynes, T. J. Bruno, and D. R. Lide, editors, in CRC Handb. Chem. Phys., 96th ed. (CRC Press, Boca Raton, FL, 2015), pp. 4-43-4-101.

26. L. A. Burton, D. Colombara, R. D. Abellon, F. C. Grozema, L. M. Peter, T. J. Savenije, G. Dennler, and A. Walsh, Chem Mat (2013).

27. O. Madelung, U. Rössler, and M. Schulz, editors, in SpringerMaterials Ser. Landolt-Börnstein Gr. III Condens. Matter, Subvolume 41C, Non-Tetrahedrally Bond. Elem. Bin. Compd. I (SpringerVerlag, Berlin/Heidelberg, 1998), pp. 1-2.

28. A. Crovetto, R. Chen, B. Ettlinger, A. C. Cazzaniga, J. Schou, O. Hansen, and C. Persson, (submitted 2016).

29. O. Madelung, U. Rössler, and M. Schulz, editors, in Non-Tetrahedrally Bond. Elem. Bin. Compd. I (Springer-Verlag, Berlin/Heidelberg, 1998), pp. 1-8.

30. A. Weber, R. Mainz, and H. W. Schock, J. Appl. Phys. 107, 013516 (2010). 
31. W. M. Haynes, T. J. Bruno, and D. R. Lide, editors, in CRC Handb. Chem. Phys., 96th ed. (Boca Raton, FL, 2015), pp. 6-88-6-116.

32. T. Ohnishi, T. Yamamoto, S. Meguro, H. Koinuma, and M. Lippmaa, J. Phys. Conf. Ser. 59, 514 (2007).

33. B. Dam, J. H. Rector, J. Johansson, J. Huijbregtse, and D. G. De Groot, J. Appl. Phys. 83, 3386 (1998).

34. T. Venkatesan, X. D. Wu, A. Inam, and J. B. Wachtman, Appl. Phys. Lett. 52, 1193 (1988).

35. C. Kittel, Introduction to Solid State Physics, p. 78, 3rd ed. (Wiley, 1966).

36. A. Kanai, K. Toyonaga, K. Chino, H. Katagiri, and H. Araki, Jpn. J. Appl. Phys. 54, 08KC06 (2015).

37. M. Nakashima, T. Yamaguchi, H. Itani, J. Sasano, and M. Izaki, Phys. Status Solidi 12, 761 (2015).

38. B. Richards, Trans. Faraday Soc. 51, 1193 (1955).

39. V. Piacente, S. Foglia, and P. Scardala, J. Alloys Compd. 177, 17 (1991). 


\section{Figure and table captions:}

Table 1: Laser and setup comparison. *All measurements with the quartz crystal microbalance were made with a target-substrate distance of $4 \mathrm{~cm}$ and a spot size of $2.2 \pm 0.1 \mathrm{~mm}^{2}$. The films at low fluence

$\left(0.2-0.5 \mathrm{~J} / \mathrm{cm}^{2}\right)$ were made with a larger spot size (up to $5 \mathrm{~mm}^{2} \pm 0.2 \mathrm{~mm}^{2}$ ) in order to make a relatively thick film within a reasonable amount of time.

Table 2: Composition of the CTS target and selected films deposited at room temperature. Uncertainties are the standard error of repeated measurements with the same instrument. The standard error on the $\mathrm{Cu} / \mathrm{Sn}$ ratio is calculated assuming that the $\mathrm{Cu}$ and $\mathrm{Sn}$ content are fully anti-correlated. All the film measurements in this table were made with the Bruker detector.

Table 3: Cohesive energy and temperature at which the vapor pressure is $1 \mathrm{~Pa}$ for the constituent elements of CTS as well as $\mathrm{SnS}$ and $\mathrm{Cu}_{2} \mathrm{SnS}_{3}$.

Figure 1: Setup. See Table 1 for comparison of the 248 and $355 \mathrm{~nm}$ setups

Figure 2: Deposition rates of CTS and SnS-rich CTS at $355 \mathrm{~nm}(\mathrm{Nd}: Y A G$ laser, $\tau=6 \mathrm{~ns})$ and $248 \mathrm{~nm}$ ( $\mathrm{KrF}$ laser, $\tau=20 \mathrm{~ns}$ ). The estimated error is similar for all the measurements, increasing proportionally with the fluence. Due to constraints in the $248 \mathrm{~nm}$ setup it was not possible to measure the deposition rate at higher fluence without changing the spot size.

Figure 3: SEM images (top and side view) of as-deposited films on Mo-coated soda-lime glass made at room temperature with $355 \mathrm{~nm}(\mathrm{a}, \mathrm{c}, \mathrm{e})$ and $248 \mathrm{~nm}(\mathrm{~b}, \mathrm{~d}, \mathrm{f})$ laser pulses. a) $355 \mathrm{~nm}$ SnS-rich CTS $1.4 \mathrm{~J} / \mathrm{cm}^{2}$ b) $248 \mathrm{~nm} \mathrm{SnS-rich} \mathrm{CTS} 1.8 \mathrm{~J} / \mathrm{cm}^{2}$ c) $355 \mathrm{~nm} \mathrm{CTS} 1.6 \mathrm{~J} / \mathrm{cm}^{2}$ d) $248 \mathrm{~nm} \mathrm{CTS} 1.6 \mathrm{~J} / \mathrm{cm}^{2}$ e) $355 \mathrm{~nm}$ CTS $0.2 \mathrm{~J} / \mathrm{cm}^{2} \mathrm{f}$ ) $248 \mathrm{~nm}$ CTS $0.2 \mathrm{~J} / \mathrm{cm}^{2}$ (note that this film was not used for EDX as it was too thin). While the $355 \mathrm{~nm}$ film shown in a) was made at $1.4 \mathrm{~J} / \mathrm{cm}^{2}$ this film was highly similar to a series of films made at $2.3 \mathrm{~J} / \mathrm{cm}^{2}$ by the same laser. Image (c) was taken with the Backscattered Electron detector while the others were taken with the more surface-sensitive Secondary Electron detectors.

Figure 4: Distribution of droplet size at 0.2 and $1.6 \mathrm{~J} / \mathrm{cm}^{2}$ with the $355 \mathrm{~nm}$ and $248 \mathrm{~nm}$ laser in a film made from the non-SnS-enriched target. Smaller droplets were present but could not be accurately 
quantified with the image processing software. Large droplets were rare and are therefore not accurately portrayed in the histograms.

Figure 5 Compositional analysis of the droplets as a function of droplet diameter for a film made from the non-SnS-enriched CTS target at $1.6 \mathrm{~J} / \mathrm{cm}^{2}$ at $248 \mathrm{~nm}$ (note that this target was $\mathrm{Cu}$-rich and Spoor relative to the ideal composition as measured by our EDX analysis; see also Table 2). The $\mathrm{Cu}, \mathrm{Sn}$, $\mathrm{S}$ content, as well as the $\mathrm{Cu} / \mathrm{S}$ ratio are given for a random selection of droplets with an average diameter larger than $1 \mu \mathrm{m}$. The composition of the target is indicated as "target", while the composition of the underlying film is indicated by "matrix". 


\begin{tabular}{|l|l|l|}
\hline Wavelength $(\boldsymbol{\lambda})$ & $\mathbf{2 4 8} \mathbf{~ n m}$ & $\mathbf{3 5 5} \mathbf{~ n m}$ \\
\hline Laser type & KrF excimer & Nd:YAG solid-state \\
\hline Pulse width (ns) & 20 & $5-7$ \\
\hline Frequency $(\mathrm{Hz})$ & 10 & 10 \\
\hline Target-substrate distance $(\mathrm{cm})$ & 4 & $4-4.5^{*}$ \\
\hline Spot size $\left(\mathrm{mm}^{2}\right)$ & $2.2 \pm 0.1^{*}$ & $2.2 \pm 0.1^{*}$ \\
\hline Fluence range $\left(\mathrm{J} / \mathrm{cm}^{2}\right)$ & $0.2-2.1$ & $0.2-2.4$ \\
\hline Duration of deposition $(\mathrm{min})$ & $45-94$ & $20-180$ \\
\hline
\end{tabular}

Table 1: Laser and setup comparison. *All measurements with the quartz crystal microbalance were made with a target-substrate distance of $4 \mathrm{~cm}$ and a spot size of $2.2 \pm 0.1 \mathrm{~mm}^{2}$. The films at low fluence $\left(0.2-0.5 \mathrm{~J} / \mathrm{cm}^{2}\right.$ ) were made with a larger spot size (up to $5 \mathrm{~mm}^{2} \pm 0.2 \mathrm{~mm}^{2}$ ) in order to make a relatively thick film within a reasonable amount of time. 


\begin{tabular}{|c|c|c|l|l|l|l|l|}
\hline & $\begin{array}{c}\text { Fluence } \\
\left(\mathrm{J} / \mathrm{cm}^{2}\right)\end{array}$ & $\begin{array}{c}\text { Spot } \\
\text { size } \\
\left(\mathrm{mm}^{2}\right)\end{array}$ & $\begin{array}{l}\text { Thickness } \\
(\mathrm{nm})\end{array}$ & $\mathrm{Cu}(\%)$ & $\mathrm{Sn}(\%)$ & $\mathrm{S}(\%)$ & $\mathrm{Cu} / \mathrm{Sn}$ \\
\hline CTS target & - & - & - & $38.6 \pm 1.0$ & $17.1 \pm 1.0$ & $44.4 \pm 0.3$ & $2.3 \pm 0.5$ \\
\hline \multirow{3}{*}{$355 \mathrm{~nm}$ laser } & 1.6 & 2.5 & 1500 & $43.3 \pm 0.4$ & $18.7 \pm 0.5$ & $38.1 \pm 0.1$ & $2.3 \pm 0.1$ \\
\cline { 2 - 9 } & 0.5 & 5 & 1000 & $28.8 \pm 0.5$ & $25.8 \pm 0.5$ & $45.5 \pm 0.1$ & $1.1 \pm 0.1$ \\
\cline { 2 - 9 } & 0.2 & 3.3 & 1200 & $27.4 \pm 0.7$ & $25.3 \pm 0.3$ & $47.3 \pm 0.5$ & $1.1 \pm 0.1$ \\
\hline \multirow{2}{*}{$248 \mathrm{~nm}$ laser } & 1.6 & 2.2 & $850-900$ & $38.9 \pm 0.6$ & $19.3 \pm 0.2$ & $41.8 \pm 0.6$ & $2.0 \pm 0.1$ \\
\cline { 2 - 9 } & 0.5 & 5 & 800 & $11.1 \pm 1$ & $29.2 \pm 2.1$ & $59.8 \pm 2.3$ & $0.4 \pm 0.1$ \\
\cline { 2 - 8 } & 0.2 & 4 & 450 & $N D$ & $N D$ & $N D$ & $N D$ \\
\hline
\end{tabular}

Table 2: Composition of the CTS target and selected films deposited at room temperature. Uncertainties are the standard error of repeated measurements with the same instrument. The standard error on the $\mathrm{Cu} / \mathrm{Sn}$ ratio is calculated assuming that the $\mathrm{Cu}$ and $\mathrm{Sn}$ content are fully anti-correlated. All the film measurements in this table were made with the Bruker detector. 


\begin{tabular}{|l|l|l|}
\hline & $\begin{array}{l}\text { Cohesive energy } \\
(\mathrm{eV} / \text { atom })[35]\end{array}$ & $\begin{array}{l}\text { Temperature at which the vapor pressure is } 1 \mathrm{~Pa}\left({ }^{\circ} \mathrm{C}\right) \\
{[25,30,31,38,39]}\end{array}$ \\
\hline $\mathrm{Cu}$ & 3.5 & 963 \\
\hline $\mathrm{Sn}$ & 3.12 & 951 \\
\hline $\mathrm{S}$ & 2.86 & low (boils at $\left.445^{\circ} \mathrm{C}\right)$ \\
\hline $\mathrm{SnS}$ & NA & 590 \\
\hline $\mathrm{Cu}_{2} \mathrm{SnS}_{3}$ & NA & Not known, higher than $\mathrm{SnS}$ \\
\hline
\end{tabular}

Table 3: Cohesive energy and temperature at which the vapor pressure is $1 \mathrm{~Pa}$ for the constituent elements of CTS as well as $\mathrm{SnS}$ and $\mathrm{Cu}_{2} \mathrm{SnS}_{3}$. 


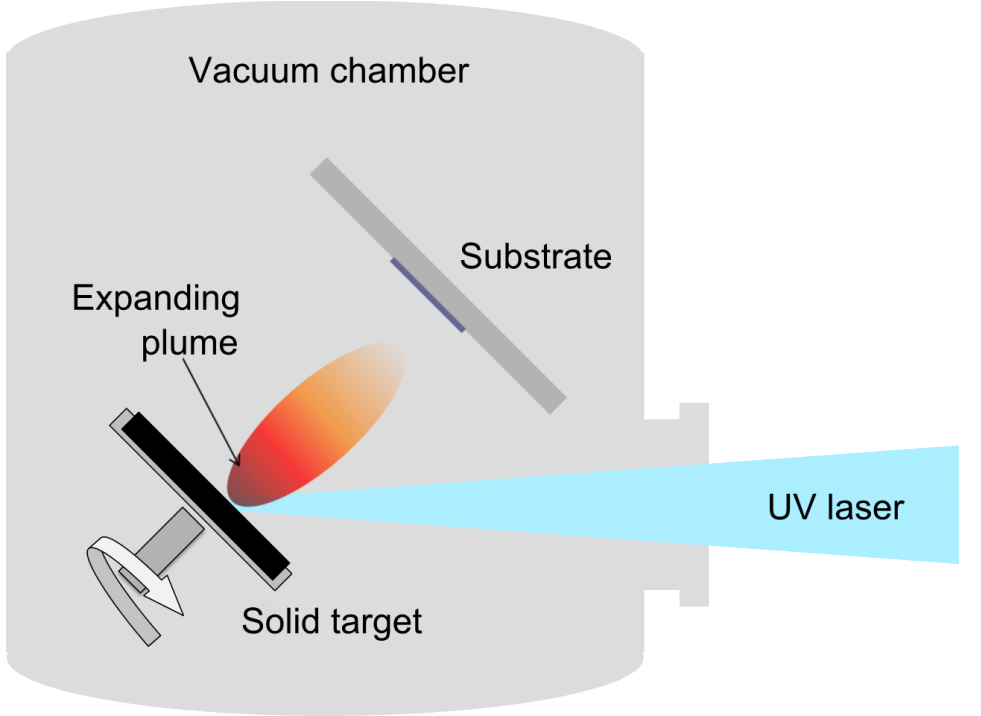

Figure 1: Setup. See Table 1 for comparison of the 248 and $355 \mathrm{~nm}$ setups 

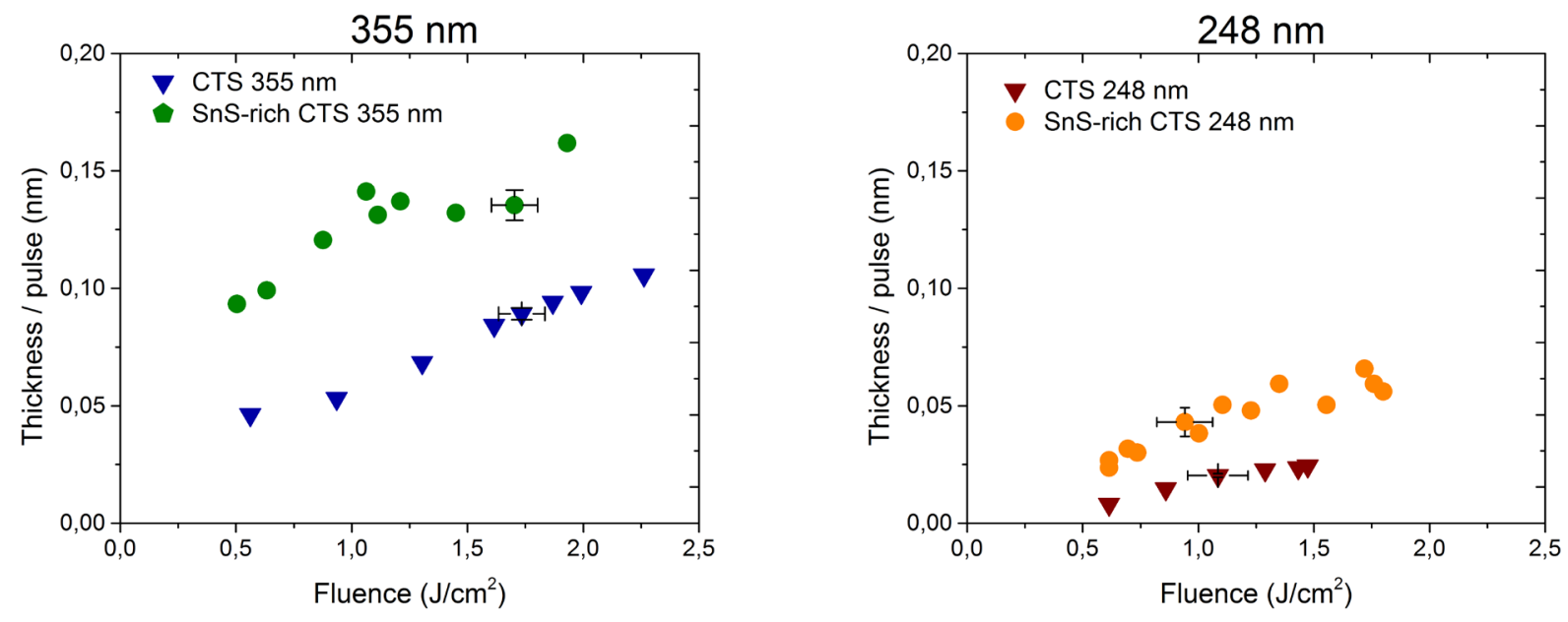

Figure 2: Deposition rates of CTS and SnS-rich CTS at $355 \mathrm{~nm}(\mathrm{Nd}: Y A G$ laser, $\tau=6 \mathrm{~ns})$ and $248 \mathrm{~nm}$ ( $\mathrm{KrF}$ laser, $\tau=20 \mathrm{~ns}$ ). The estimated error is similar for all the measurements, increasing proportionally with the fluence. Due to constraints in the $248 \mathrm{~nm}$ setup it was not possible to measure the deposition rate at higher fluence without changing the spot size. 

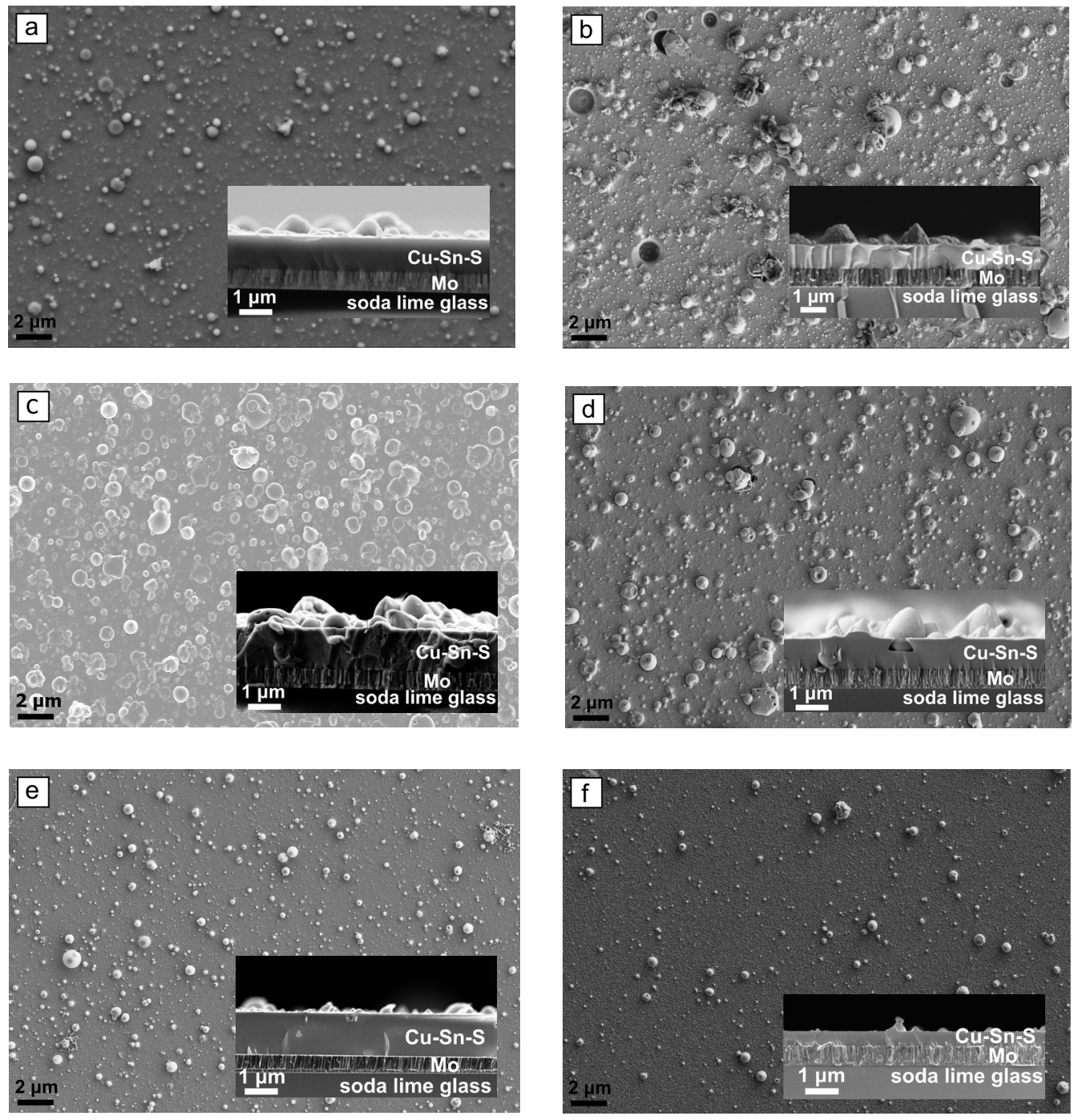

Figure 3: SEM images (top and side view) of as-deposited films on Mo-coated soda-lime glass made at room temperature with $355 \mathrm{~nm}(\mathrm{a}, \mathrm{c}, \mathrm{e})$ and $248 \mathrm{~nm}(\mathrm{~b}, \mathrm{~d}, \mathrm{f})$ laser pulses. a) $355 \mathrm{~nm} \mathrm{SnS}$-rich CTS $1.4 \mathrm{~J} / \mathrm{cm}^{2}$ b) $248 \mathrm{~nm} \mathrm{SnS-rich} \mathrm{CTS} 1.8 \mathrm{~J} / \mathrm{cm}^{2}$ c) $355 \mathrm{~nm} \mathrm{CTS} 1.6 \mathrm{~J} / \mathrm{cm}^{2}$ d) $248 \mathrm{~nm} \mathrm{CTS} 1.6 \mathrm{~J} / \mathrm{cm}^{2} \mathrm{e}$ ) $355 \mathrm{~nm}$ CTS $0.2 \mathrm{~J} / \mathrm{cm}^{2} \mathrm{f}$ ) $248 \mathrm{~nm}$ CTS $0.2 \mathrm{~J} / \mathrm{cm}^{2}$ (note that this film was not used for EDX as it was too thin). While the $355 \mathrm{~nm}$ film shown in a) was made at $1.4 \mathrm{~J} / \mathrm{cm}^{2}$ this film was highly similar to a series of films made at $2.3 \mathrm{~J} / \mathrm{cm}^{2}$ by the same laser. Image (c) was taken with the Backscattered Electron detector while the others were taken with the more surface-sensitive Secondary Electron detectors. 

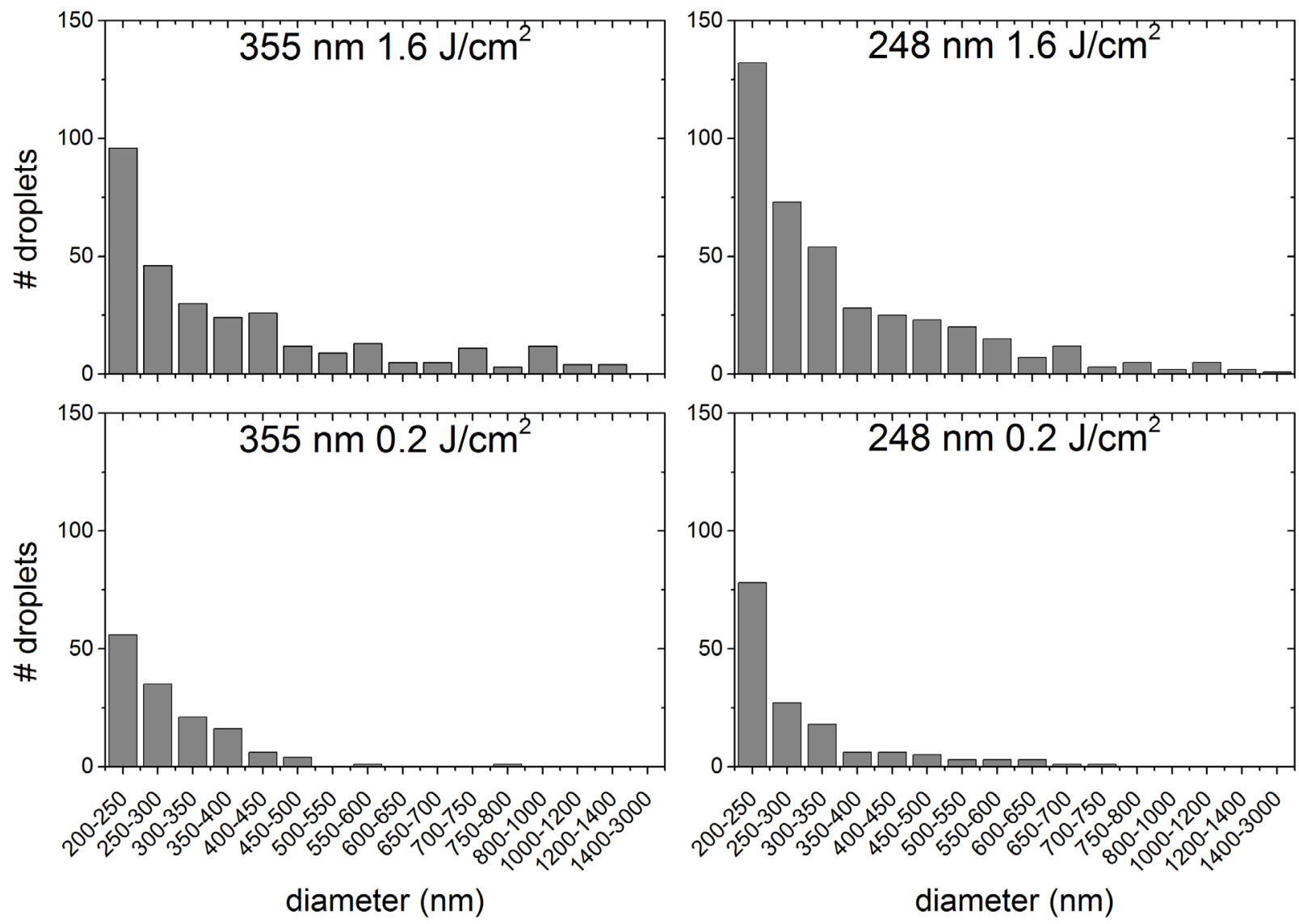

Figure 4: Distribution of droplet size at 0.2 and $1.6 \mathrm{~J} / \mathrm{cm}^{2}$ with the $355 \mathrm{~nm}$ and $248 \mathrm{~nm}$ laser in a film made from the non-SnS-enriched target. Smaller droplets were present but could not be accurately quantified with the image processing software. Large droplets were rare and are therefore not accurately portrayed in the histograms. 

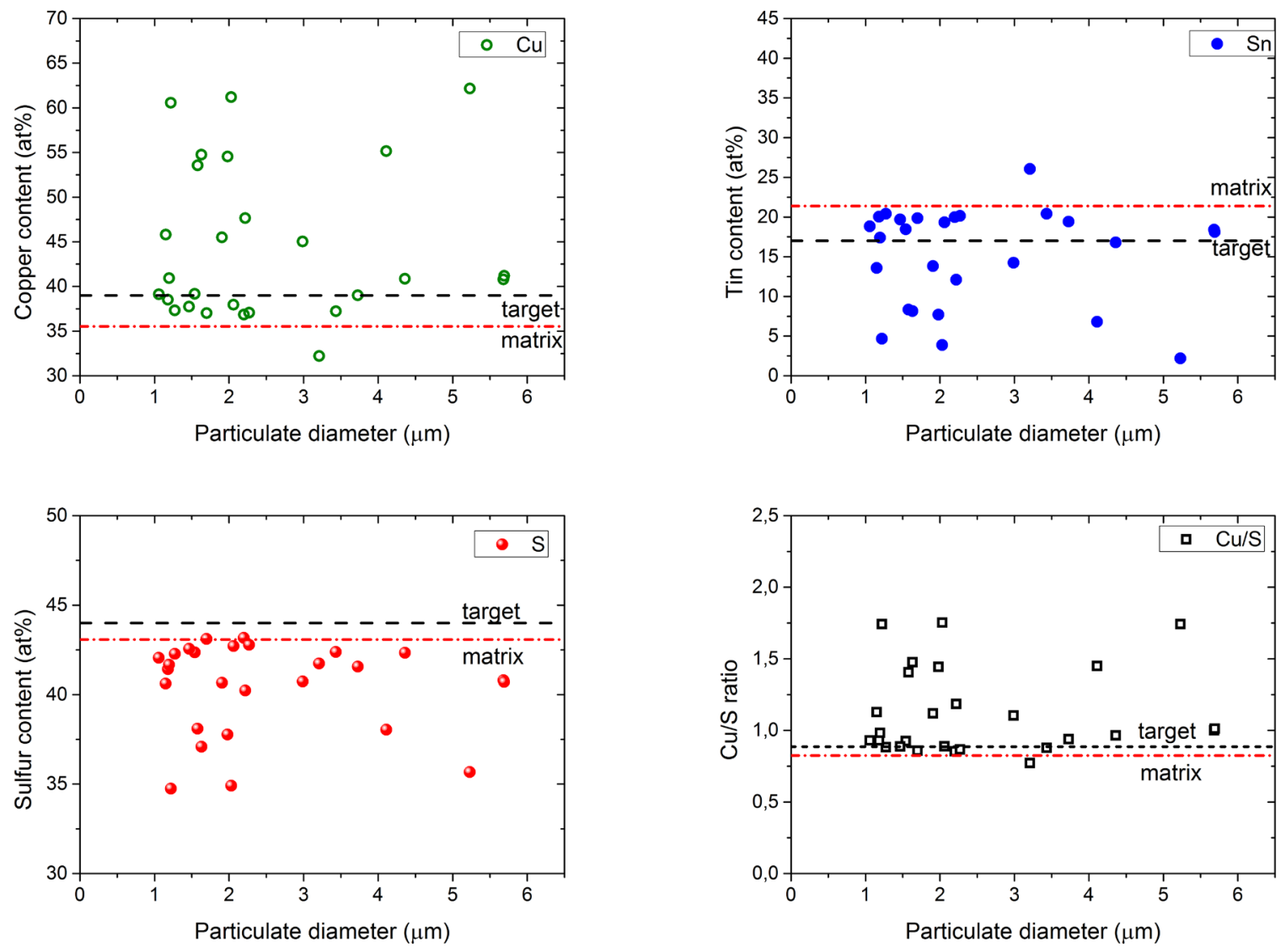

Figure 5: Compositional analysis of the droplets as a function of droplet diameter for a film made from the non-SnS-enriched CTS target at $1.6 \mathrm{~J} / \mathrm{cm}^{2}$ at $248 \mathrm{~nm}$ (note that this target was $\mathrm{Cu}$-rich and Spoor relative to the ideal composition as measured by our EDX analysis; see also Table 2). The $\mathrm{Cu}, \mathrm{Sn}$, $\mathrm{S}$ content, as well as the $\mathrm{Cu} / \mathrm{S}$ ratio are given for a random selection of droplets with an average diameter larger than $1 \mu \mathrm{m}$. The composition of the target is indicated as "target", while the composition of the underlying film is indicated by "matrix". 